\title{
'Omics' and Plant Responses to Botrytis cinerea
}

\author{
Synan F. AbuQamar ${ }^{1 *}$, Khaled Moustafa ${ }^{2}$ and Lam-Son P. Tran ${ }^{3,4 *}$ \\ ${ }^{1}$ Department of Biology, United Arab Emirates University, Al Ain, UAE, ${ }^{2}$ Conservatoire National des Arts et Métiers, Paris, \\ France, ${ }^{3}$ Plant Abiotic Stress Research Group \& Faculty of Applied Sciences, Ton Duc Thang University, Ho Chi Minh City, \\ Vietnam, ${ }^{4}$ Signaling Pathway Research Unit, RIKEN Center for Sustainable Resource Science, Yokohama, Japan
}

\section{OPEN ACCESS}

Edited by:

Manoj Prasad,

National Institute of Plant Genome

Research, India

Reviewed by:

Shawkat Ali,

King Abdullah University of Science and Technology, Saudi Arabia Anand K. Soshee, Nanyang Technological University, Singapore

*Correspondence: Synan F. AbuQamar sabuqamar@uaeu.ac.ae Lam-Son P. Tran

sontran@tdt.edu.vn; son.tran@riken.jp

Specialty section: This article was submitted to Plant Nutrition, a section of the journal Frontiers in Plant Science

Received: 19 September 2016 Accepted: 20 October 2016 Published: 15 November 2016

Citation: AbuQamar SF, Moustafa K and Tran L-SP (2016) 'Omics' and Plant Responses to Botrytis cinerea.

Front. Plant Sci. 7:1658. doi: 10.3389/fpls.2016.01658
Botrytis cinerea is a dangerous plant pathogenic fungus with wide host ranges. This aggressive pathogen uses multiple weapons to invade and cause serious damages on its host plants. The continuing efforts of how to solve the "puzzle" of the multigenic nature of $B$. cinerea's pathogenesis and plant defense mechanisms against the disease caused by this mold, the integration of omic approaches, including genomics, transcriptomics, proteomics and metabolomics, along with functional analysis could be a potential solution. Omic studies will provide a foundation for development of genetic manipulation and breeding programs that will eventually lead to crop improvement and protection. In this mini-review, we will highlight the current progresses in research in plant stress responses to $B$. cinerea using high-throughput omic technologies. We also discuss the opportunities that omic technologies can provide to research on $B$. cinerea-plant interactions as an example showing the impacts of omics on agricultural research.

\section{Keywords: Arabidopsis, biotic stress, Botrytis cinerea, omics, metabolomics, proteomics, transcriptomics}

\section{INTRODUCTION}

Botrytis cinerea, often known as gray mold, is a necrotrophic fungal pathogen that kills its host plant cells, and then colonizes the dead tissues. It can infect more than 200 crop hosts, causing enormous economic damage on important crops, such as tomatoes, berries and petunia flowers (FernándezAcero et al., 2011; Elad et al., 2015). As a result, B. cinerea has been considered the second most dangerous phytopathogen worldwide (Dean et al., 2012). The long-established approach of treating infections caused by this pathogen has been the use of large amounts of fungicides during the seasonal crop cycle (De Miccolis Angelini et al., 2014). This method, however, has become impractical due to the development of fungal resistance and the public health safety concerns associated with fungicide uses. Recently, huge efforts have been made to engineer resistant crop plants to $B$. cinerea in an environmentally sustainable, safe and cost-effective manner.

As an opportunist fungus, $B$. cinerea attacks weak, damaged or senescent tissues through wound or previously infected sites (Elad and Evensen, 1995). B. cinerea has developed sophisticated penetration, infection and colonization strategies to suppress plant defenses (for review, see van Kan, 2006), which are mediated by lytic enzymes, toxins, stress-induced reactive oxygen species (ROS), necrosis-secreted proteins and a large group of secondary metabolites (Choquer et al., 2007). On the other hand, plant defense mechanisms can restrain these strategies through preformed (constitutive) or induced (physical and chemical) barriers (for review, see Mengiste et al., 2010). Plant cuticle and cell wall serve as the first line of defense against this pathogen (Chassot et al., 2007; AbuQamar et al., 2013; AbuQamar, 2014). Chemical defenses, 
such as the constitutively present phytoanticipins and phytoalexins that are produced de novo upon infection, also provide protection (VanEtten et al., 1994). Pathogenesisrelated (PR) proteins, defensins, antimicrobial compounds are accumulated in response to infection (van Loon and Van Strien, 1999; van Loon et al., 2006). Moreover, phytohormones, including salicylic acid, jasmonic acid, ethylene, abscisic acid (ABA), brassinosteroids, auxin, cytokinins, gibberellins and strigolactone, contribute, individually or co-operately, in mediating plant responses to B. cinerea (Thomma et al., 1998; Audenaert et al., 2002; Ferrari et al., 2003; Torres-Vera et al., 2014; AbuQamar et al., 2016).

Recent research technologies have developed efficient omic tools to unravel the molecular mechanisms of plant responses to $B$. cinerea and to improve disease diagnosis and fungal detection. Genome is a complete set of chromosomes, which contains all genes in an organism. Transcriptome describes the entire set of coding and non-coding RNAs, whereas proteome is the collection of proteins derived from a genome. Metabolome are all metabolites found in a biological system (e.g., cell, tissue, organ, or organism). Advances in high-throughput DNA sequencing, RNA sequencing (RNAseq), mass spectrometry (MS), and nuclear magnetic resonance (NMR) at the genomic, transcriptomic, proteomic and metabolomic levels, and through the multi-omics (also known as integrated-omics) (Shiratake and Suzuki, 2016), have made possible the development of such data into a systems biology-based framework (Figure 1). Highthroughput-next generation sequencing (HT-NGS) technologies, ranging from RNAseq to whole-genome sequencing, are fast, sensitive and accurate tools for detection of $B$. cinerea genome from symptomatic or asymptomatic plants and understanding defense mechanisms associated with fungal infections in planta (Smith et al., 2014). Moreover, HT-NGS techniques have promising applications at the molecular plant- $B$. cinerea interaction research. Applications of advanced technologies have enabled us to gain insights into fungal genome variability, pathogenic diversity, host range and evolution within $B$. cinerea's host plant. Availability of omic data will substantially advance our understanding of $B$. cinerea infection strategies, thereby enhancing future predictions of plant responses to the gray mold disease (Hahn et al., 2014; Jiang et al., 2016). In this review, we will overview the recent applications and impacts of omic technologies on agricultural research, focusing on plant$B$. cinerea interactions. Future studies should be directed at moving from smaller (laboratory) scales using omic tools to larger (field) scales using genetic engineering and breeding strategies to develop low cost and durable disease-resistant crops.

\section{GENOMICS}

DNA sequencing approaches remain cost-effective, and both the traditional Sanger dideoxy nucleotide sequencing and pyrosequencing have proved their success for de novo and confirmatory sequencing (Pareek et al., 2011). Pyrosequencing is usually used for single nucleotide polymorphism (SNP) analysis and sequencing of short stretches of DNA (Fakruddin and
Chowdhury, 2012). The NGS technologies -Illumina/Solexa, Ion Torrent Personal Genome Machine (PGM) and Pacific Biosciences (PacBio) sequencing methods- have revolutionized genomic and genetic research (for review, see Heather and Chain, 2016). B. cinerea has become a model for dissecting the complexity of necrotrophs and broad host-range pathogenicity. $B$. cinerea strains may survive different environmental stresses that inhibit or promote infections on their host plant (Ahlem et al., 2012). To gain an in-depth understanding of B. cinereaplant interactions at whole genome level, Syngenta AG initiated genome sequence project for B. cinerea T4 and B05.10 strains, obtaining a genome size of $37.9 \mathrm{Mbp}$ (14,270 genes) and $38.8 \mathrm{Mbp}$ (13,664 genes), respectively, using Illumina HiSeq2000 technology (Amselem et al., 2011; Staats and van Kan, 2012). A recent report using a combination of two sequencing technologies, namely Illumina and PacBio, has assembled a gapless genome sequence of $B$. cinerea strain B05.10 (van Kan et al., 2016). This assembly is comprised of 18 chromosomes, a genetic map of 4153 centimorgan and approximately 75,000 SNP markers. Comparative analysis of the genome sequences revealed high sequence identity and gene arrangement similarity between B. cinerea and Sclerotinia sclerotiorum, but different mating behavior and compatibility systems between these pathogenic fungi (Amselem et al., 2011), suggesting no unique features that distinguished them as pathogenic and saprotrophic fungi. Differences in the number and diversity of secondary metabolism (SM) gene clusters are key distinctions between the genomes of these two pathogenic species, and thus attributing to their differential environmental habitats. For example, S. sclerotiorum produces $28 \mathrm{SM}$ enzymes, whereas $B$. cinerea secrets 43 . In addition, botrydial, botcinic acid, and ABA biosynthetic genes were characterized in B. cinerea, but not in S. sclerotiorum. The regulation of sexual reproduction, content of transposable elements, and the sequence and organization of mating-type (MAT) loci between the two species have also been distinguished. Yet the genomes of the two species show high sequence identity and similar gene arrangements, implicating no unique features between the genomes of $S$. sclerotiorum and B. cinerea, which could be distinguished as a "clear-cut" evidence of their aggressive behavior and multigenic nature of pathogenesis.

A draft genome of $B$. cinerea $\mathrm{BcDW} 1$ strain, isolated from botrytized grapes, was also sequenced (Blanco-Ulate et al., 2013). Candidate secreted proteins involved in plant tissue penetration and decomposition, including glycoside hydrolases, carbohydrate esterases, and polysaccharide lyases were identified as compared with T4 and B05.10 genomes. Other secreted laccases and carboxylesterases were also detected for their relevance to noble rot (Magyar, 2011). Comparative analyses of the genome sequences of the $B$. cinerea strains have been proved to be useful for elucidating the genetic and environmental bases of $B$. cinereahost specificity (Atwell et al., 2015). The genomes of 13 different $B$. cinerea isolates have been re-sequenced to measure their genetic diversities, which pointed out the fact of the broad host range of the species, and their potential ability to adapt to new hosts.

Arabidopsis is a small flowering plant that offers important advantages for basic research in genetics and molecular biology. 

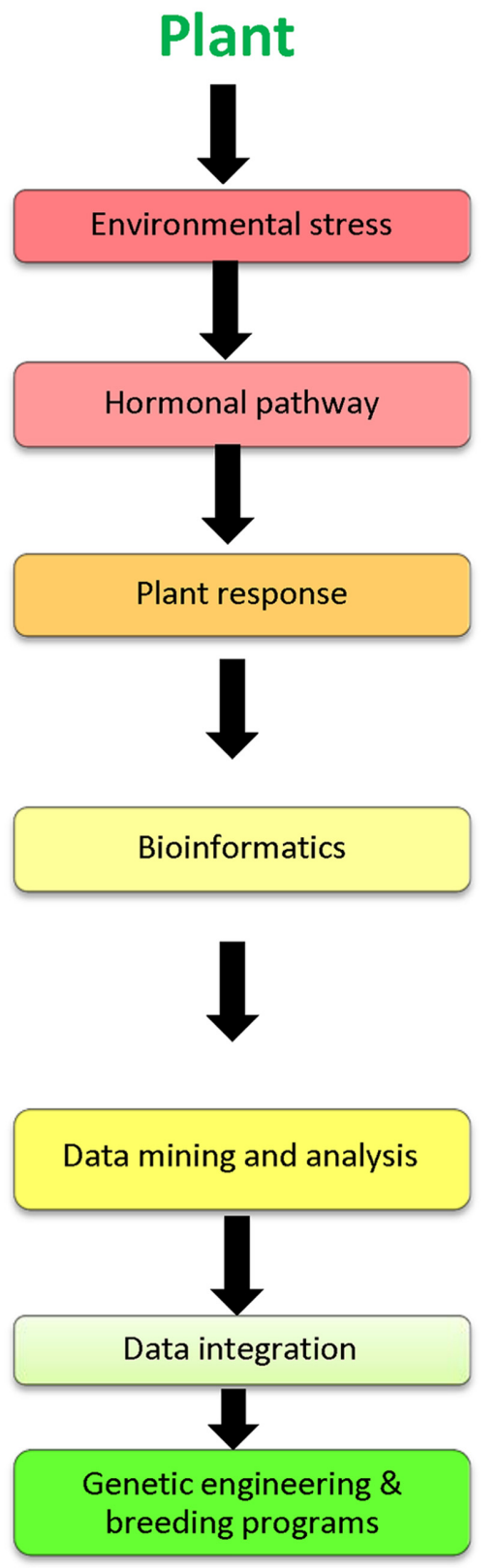

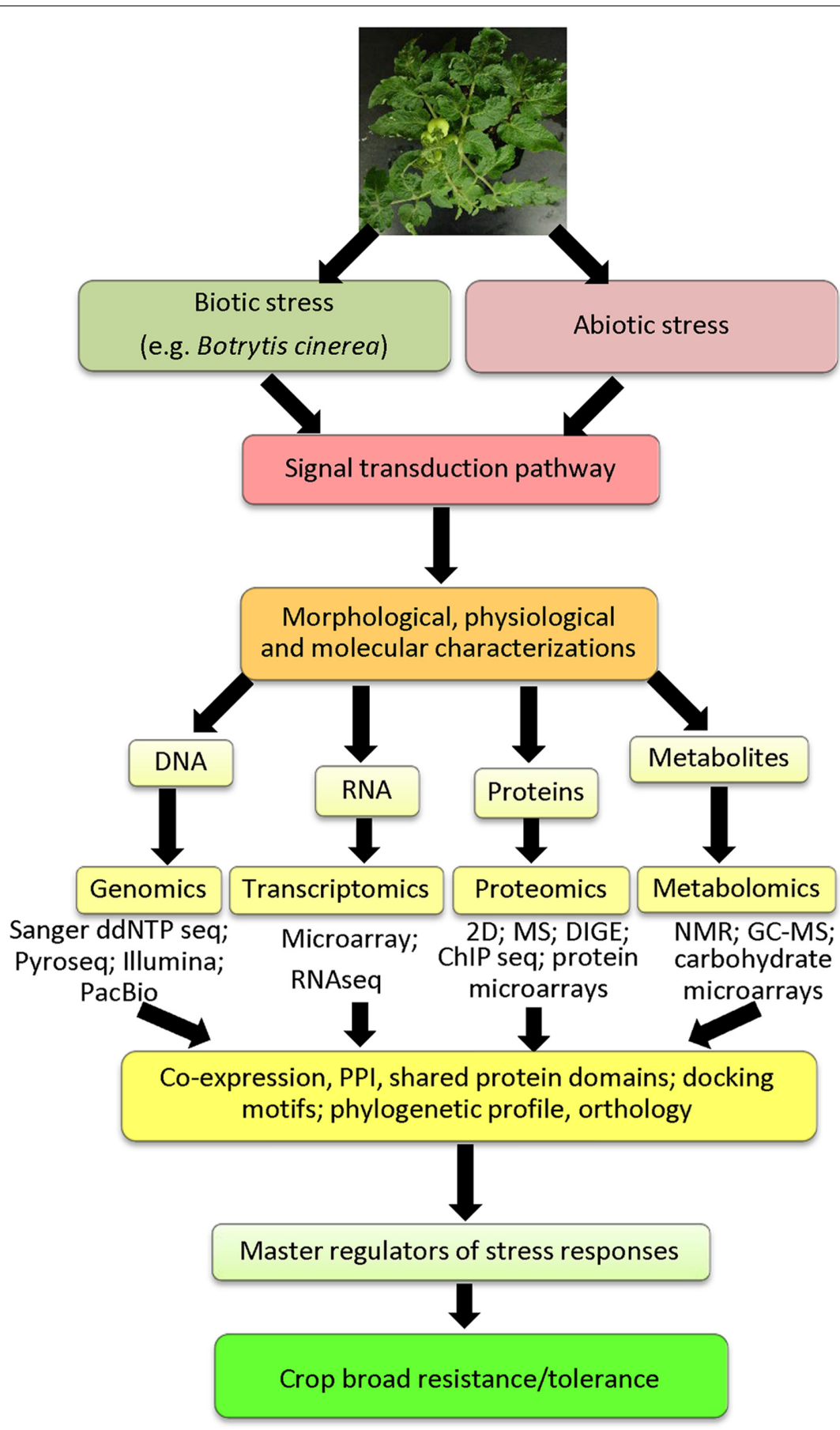

FIGURE 1 | Schematic representation of omic approaches used in improvement of plant resistance/tolerance to biotic and abiotic stresses. Sanger ddNTP seq, Sanger dideoxy nucleotide; Pyroseq, pyrosequencing; Illumina, Illumina sequencing; PacBio, Pacific Biosciences; RNAseq, RNA sequencing; ChIP seq, chromatin immunoprecipitation sequencing; 2D, 2-dimensional gel electrophoresis; DIGE, differential gel electrophoresis; MS, mass spectrometry; NMR, nuclear magnetic resonance; GC-MS, gas chromatography-mass spectrometry; PPI, protein-protein interaction.

Arabidopsis genome sequence was first completed in 2000, with a genome size of $\sim 135 \mathrm{Mbp}$ (Arabidopsis Genome Initiative, 2000). A full public database of the Arabidopsis complete genome, genome maps, genetic and physical markers, gene structure and gene expression, DNA and seed stocks, can be accessed via The Arabidopsis Information Resource (TAIR ${ }^{1}$ ) database. The "flexibility" of the Arabidopsis genome allows this plant to adapt to various environmental conditions. This is evidenced

${ }^{1}$ www.arabidopsis.org 
when the 1001 Genomes Project investigated the wholegenome sequence variation among 100 Arabidopsis ecotypes from different geographical regions (Cao et al., 2011). The first full genome sequence of tomato (Solanum lycopersicum) "Heinz 1706" was achieved in 2012 (Tomato Genome Consortium, 2012). Sequences and arrangements of 35,000 genes on 12 chromosomes have been described. In 2014, the genomes of 360 tomato varieties were also sequenced (Lin et al., 2014). Bolger et al. (2014) have sequenced the stress-tolerant tomato wild species, S. pennellii, and identified candidate genes and transposable elements that would play a crucial role in survival in arid habitats. In 2011, the woodland strawberry (Fragaria vesca) was sequenced (Shulaev et al., 2011). The relatively smallsized genome (240 Mbp; 35,000 genes) of this perennial plant shares substantial sequence identity with those of the cultivated strawberry $(F . \times$ ananassa $)$ and other rosaceous plants. The genetic map of the grape (Vitis vinifera) was completed in 2007 by the shotgun sequencing approach (Jaillon et al., 2007). In addition, genome sequence of chickpea (Cicer arietinum) was also assembled by two independent groups (Jain et al., 2013; Varshney et al., 2013; Parween et al., 2015; Thudi et al., 2016). The releases of genome sequences of $B$. cinerea and its hosts have helped identify candidate genes associated with virulence of $B$. cinerea and potential target genes associated with resistance in host crops. The genome sequences of $B$. cinerea hosts have provided us a means to study and gain more insights into plant defense system against this "nasty" fungus.

Genome sequencing will help breeders look at the "blueprint" of crop plants to produce resistant hybrids. As long as the genomes of the fungus and its host plants have been sequenced, a whole-genome gene expression analysis will identify the critical factors in B. cinerea pathogenesis and disease resistance mechanisms in plants, pathogen-derived effectors, and the molecular events associated with infection processes in planta.

\section{TRANSCRIPTOMICS}

Comparative gene expression analyses can be used to mine the regulatory information through transcriptomic methods to generate data on stress modulations of gene expression in plants. High-throughput methods used for transcriptomics include hybridization-based (microarray technology) and sequencingbased approaches (RNAseq), which allow us to carry out transcriptomic analyses in both model and non-model organisms (Warren et al., 2007). Generally, transcriptomic measures are best suited for early identification of cell responses to an individual or multiple stress(es). Plant responses to B. cinerea undergo transcriptional reprograming, showing that over $12 \%$ of the Arabidopsis genome are differentially expressed genes (DEGs), of which 1498 (7\%) and 1138 (5\%) were reported to be $B$. cinerea-induced and-repressed genes, respectively (Sham et al., 2014, 2015). A number of DEGs, which were shown to be implicated in $B$. cinerea defense, encode transcription factors, including WRKYs (Birkenbihl et al., 2012; Liu et al., 2015), APETALA2/ethylene response factors (AP2/ERFs) (Son et al., 2012; Maruyama et al., 2013), TGAs (Windram et al., 2012; Sham et al., 2014), NACs (Wang et al., 2009), and MYBs (Ramírez et al., 2011). Several studies focusing on the transcriptional regulation of responses to multiple stresses have identified commonly regulated genes responsive to both $B$. cinerea infection and simultaneous abiotic stresses, such as drought, heat, or salinity, in Arabidopsis using microarray analyses (Atkinson and Urwin, 2012; Sham et al., 2015). In tomato, a transcriptomic study using RNAseq has distinguished the natural variation among wild Solanum species (Smith et al., 2014). Following $B$. cinerea infection, photosynthetic and metabolic processes were suppressed, whereas defense-related genes, such as those encoding PR protein 1 (PR1), $\beta$-1,3-glucanase and subtilisin-like protease, were simultaneously induced in the highly B. cinerea-resistant species, S. lycopersicoides. Expression of a number of secondary metabolites- and defense-related genes in S. lycopersicum were also up-regulated by B. cinerea infection.

Recently, transcriptomics studies and genetic mutagenesis have been developed to generate tagged mutants for reverse genetics purposes (Figure 2). Transcriptomics enables us to identify potential candidate genes functioning in plant defense, whereas mutant lines with knockout and/or overexpression traits allow us to elucidate their function in the defense response. Botrytis-induced kinase 1 (BIK1), responsive to dehydration 20

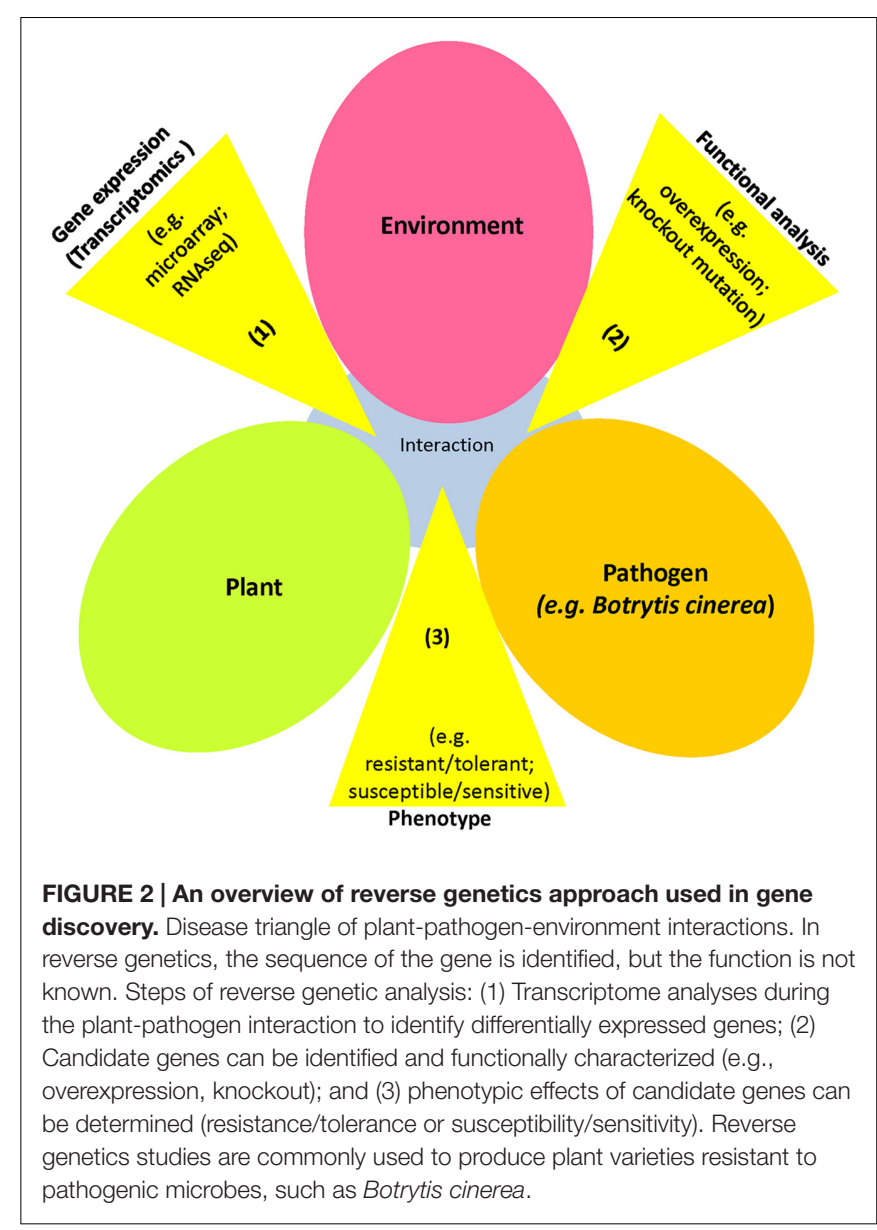


(RD20), pentatricopeptide repeat protein for germination on $\mathrm{NaCl}(P G N)$, and expansin-like A2 (EXLA2) were identified as $B$. cinerea-responsive genes, and their mutants exhibited altered susceptibility to necrotrophic pathogens (Veronese et al., 2006; Laluk et al., 2011; AbuQamar et al., 2013; AbuQamar, 2014; Sham et al., 2015). Moreover, the Mediator 18 (MED18), identified using RNAseq, was shown to modulate plant immunity and responses to hormones (Lai et al., 2014). These B. cinerearesponsive genes appear to be important in the pathogenesis of $B$. cinerea, as well as plant responses to various abiotic stressors (Lai et al., 2014). These findings confirm the existence of crosstalk in plant responses to $B$. cinerea infection and abiotic stress, involving various signaling hormone pathways, which affects photosynthesis, protein synthesis and transport, thereby highlighting the complexity of cellular signaling networks in plants (Birkenbihl et al., 2012; Windram et al., 2012; AbuQamar et al., 2016). The integration of genomics and transcriptomics, along with proteomics will identify biomarkers for biotic and abiotic stresses. This can be achieved by considering comparison of two (or more) different omic data sets (e.g., transcriptomic and proteomic data) to create a reference data set sharing the same functional context (Haider and Pal, 2013). This approach can build a dynamic model of functional features of biological processes/pathways involving transcripts and proteins.

\section{PROTEOMICS}

Protein identification can be done in a serial fashion to monitor the presence, absence or the overall quantity of a protein. Proteomic approaches can be used to investigate changes in protein levels under adverse stress conditions. Protein microarrays, for example, were successfully used to identify potential proteins interacting with calmodulin and calmodulin-like proteins (Popescu et al., 2007). However, a challenge in the construction of protein microarrays is that the proteins must be produced and purified from biological systems that allow proteins undergo posttranslational modifications and folding so that they retain their functions on the chip (Popescu et al., 2007). Proteins can also be separated using 1dimensional (based on size only) or 2-dimensional (based on charge and size) protein gel electrophoresis (Gallagher, 2006; Rabilloud and Lelong, 2011), or chromatography (e.g., ultrahigh speed MALDI-TOF and high mass resolution MALDI FTICR imaging MS) (Spraggins et al., 2016). A comparative proteomic analysis of two B. cinerea strains 1.11 and 2100 identified proteins that play crucial roles in their differential virulence, including housekeeping enzymes, such as malate and glyceraldehyde dehydrogenases (Fernández-Acero et al., 2007). In another research using shotgun proteomics, 126 proteins were altered in the proteome secreted by $B$. cinerea, of which 13 were pectinases that are involved in cell wall degradation (Shah et al., 2009). More recently, comparative proteomic analysis identified significant differences in the secretomes of $B$. cinerea strain B05.10 between $\mathrm{pH} 4-6$ ( $\mathrm{Li}$ et al., 2012). Proteins related to proteolysis were induced at
$\mathrm{pH} 4$, whereas cell wall degrading enzymes were accumulated at $\mathrm{pH} 6$ (Li et al., 2012). Proteomics of tomato fruits infected by $B$. cinerea revealed changes in 186 proteins in mature green wild-type fruit, which were unaltered in red ripe (RR) wild-type and ripening inhibited (rin) mutant. However, fewer defense-related proteins were changed in mature green wild-type fruit than in $\mathrm{RR}$ and rin fruits (Shah et al., 2012).

\section{METABOLOMICS}

Metabolomics may identify phenotypic effects of stresses on plants by measuring the abundance of metabolites, which fall downstream of genomic, transcriptomic and proteomic variations, and thus providing a dynamic measure of phenotypic responses to environmental cues (for reviews, see Hasanuzzaman et al., 2013; Hong et al., 2016). Metabolomic profiling is often performed with NMR, or MS, such as gas chromatographyMS (GC-MS) and liquid chromatography-MS (LC-MS) (for reviews, see Tuteja et al., 2011; Gathungu et al., 2014). Pathogen sensing, enzyme activities, and protein/antibodies and carbohydrate-binding screening can also be detected by carbohydrates and metabolites microarrays (Yadav et al., 2015). Metabolomic approaches have the ability to measure a broader array of small-molecules when plants are subjected to adverse conditions (Zhao et al., 2016). Primary metabolites, such as sugars, amino acids and Krebs cycle intermediates, are mainly involved in plant responses to abiotic stresses. Their changes are considered as indications of photosynthetic dysfunction and/or osmotic readjustment (Arbona et al., 2013). Secondary metabolites, on the other hand, respond to particular stress conditions, such as pathogens, antioxidants, ROS scavengers, coenzymes, and regulatory molecules.

The induction of secondary metabolites by several abiotic stressors could also be an effective mechanism of cross-protection against biotic threats, providing a link between abiotic and biotic stress responses. For example, Arabidopsis plants co-treated with UV-B and flagellin effector flg22 showed accumulation of flavonols and enhanced resistance to B. cinerea (Moura et al., 2010), indicating that induced flavonols might play a role in protecting plants against biotic stressors. Like other necrotrophic fungi, B. cinerea often produces unspecific phytotoxins, including secondary metabolites, as "killing" weapons to cells from a range of plant species. Over 40 clusters of genes were identified in $B$. cinerea, which were dedicated to the synthesis of polyketides, terpenes, non-ribosomal peptides and alkaloids, indicating that $B$. cinerea has the potential to produce many metabolites (Collado and Viaud, 2016). Global metabolites profiling using ${ }^{1} \mathrm{H}$ NMR reveals significant metabolic variations between healthy and botrytized grape berries (Hong et al., 2012). Similar to healthy berries, botrytized ones accumulated high levels of proline, glutamate, arginine, and alanine; whereas unlike healthy ones, botrytized berries showed large degradation of phenylpropanoids, flavonoids, sucrose producing glycerol, gluconic acid, and succinate. Similarly, significant changes in 
primary and SM in tomato were reported to be associated with B. cinerea infection (Camañes et al., 2015), suggesting a prominent metabolic reprograming. The remarkable metabolic changes in Arabidopsis, grapes and tomato upon infection with B. cinerea cause metabolic perturbations both in the plant and the fungal pathogen.

\section{CONCLUSION}

There is no doubt that omics is providing insights to the molecular mechanisms of plant resistance to pathogens and tolerance to environmental stresses for better disease management. Scientists are making a great effort to link genes with traits to improve resistance of cultivars and understand the mechanisms of disease resistance. Omics enables us to "translate" the complex interactions among genes (genomics), mRNA (transcriptomics), proteins (proteomics), and metabolites

\section{REFERENCES}

AbuQamar, S. (2014). Expansins: cell wall remodeling proteins with a potential function in plant defense. J. Plant Biochem. Physiol. 2:e118. doi: 10.4172/23299029.1000e118

AbuQamar, S., Ajeb, S., Sham, A., Enan, M. R., and Iratni, R. (2013). A mutation in the expansin-like A2 gene enhanced resistance to necrotrophic fungi and hypersensitivity to abiotic stress in Arabidopsis thaliana. Mol. Plant Pathol. 14, 813-827. doi: 10.1111/mpp.12049

AbuQamar, S., Moustafa, K., and Tran, L.-S. P. (2016). Mechanisms and strategies of plant defense against Botrytis cinerea. Crit. Rev. Biotech. (accepted).

Ahlem, H., Mohammed, E., Badoc, A., and Ahmed, L. (2012). Effect of pH, temperature and water activity on the inhibition of Botrytis cinerea by Bacillus amyloliquefaciens isolates. Afr. J. Biotechnol. 11, 2210-2217.

Amselem, J., Cuomo, C. A., van Kan, J. A. L., Viaud, M., Benito, E. P., Couloux, A., et al. (2011). Genomic analysis of the necrotrophic fungal pathogens Sclerotinia sclerotiorum and Botrytis cinerea. PLoS Genet. 7:e1002230. doi: 10.1371/journal.pgen.1002230

Arabidopsis Genome Initiative (2000). Analysis of the genome sequence of the flowering plant Arabidopsis thaliana. Nature 408, 796-815. doi: $10.1038 / 35048692$

Arbona, V., Manzi, M., de Ollas, C., and Gómez-Cadenas, A. (2013). Metabolomics as a tool to investigate abiotic stress tolerance in plants. Int. J. Mol. Sci. 14, 4885-4911. doi: 10.3390/ijms14034885

Atkinson, N. J., and Urwin, P. E. (2012). The interaction of plant biotic and abiotic stresses: from genes to the field. J. Exp. Bot. 63, 3523-3543. doi: $10.1093 /$ jxb/ers 100

Atwell, S., Corwin, J. A., Soltis, N. E., Subedy, A., Denby, K. J., and Kliebenstein, D. J. (2015). Whole genome resequencing of Botrytis cinerea isolates identifies high levels of standing diversity. Front. Microbiol. 56:996. doi: 10.3389/fmicb.2015.00996

Audenaert, K., De Meyer, G. B., and Höfte, M. M. (2002). Abscisic acid determines basal susceptibility of tomato to Botrytis cinerea and suppresses salicylic acid-dependent signaling mechanisms. Plant Physiol. 128, 491-501. doi: $10.1104 /$ pp. 010605

Birkenbihl, R. P., Diezel, C., and Somssich, I. E. (2012). Arabidopsis WRKY33 is a key transcriptional regulator of hormonal and metabolic responses toward Botrytis cinerea infection. Plant Physiol. 159, 266-285. doi: 10.1104/pp.111.192641

Blanco-Ulate, B., Allen, G., Powell, A. L. T., and Canti, D. (2013). Draft genome sequence of Botrytis cinerea BcDW1, inoculum for noble rot of grape berries. Genome Announc. 1:e252-13. doi: 10.1128/genomeA.00252-13

Bolger, A., Scossa, F., Bolger, M. E., Lanz, C., Maumus, F., Tohge, T., et al. (2014). The genome of the stress-tolerant wild tomato species Solanum pennelli. Nat. Genet. 46, 1034-1038. doi: 10.1038/ng.3046 (metabolomics) into improvement of phenotypes, leading to enhanced crop productivity. Through omic technologies, the consistency and predictability of plant genetic engineering and breeding will be significantly improved by reducing the time and expense of producing resistant crops against $B$. cnerea.

\section{AUTHOR CONTRIBUTIONS}

SA and L-ST wrote the manuscript, with input and editing from KM.

\section{FUNDING}

This work was supported by the UAEU Program for Advanced Research (Grant \#: 21S091); and the Khalifa Center for Biotechnology and Genetic Engineering-UAEU (Grant \#: 31R081) to SA.

Camañes, G., Scalschi, L., Vicedo, B., González-Bosch, C., and García-Agustín, P. (2015). An untargeted global metabolomic analysis reveals the biochemical changes underlying basal resistance and priming in Solanum lycopersicum, and identifies 1-methyltryptophan as a metabolite involved in plant responses to Botrytis cinerea and Pseudomonas syringae. Plant J. 84, 125-139. doi: 10.1111/tpj.12964

Cao, J., Schneeberger, K., Ossowski, S., Günther, T., Bender, S., Fitz, J., et al. (2011). Whole-genome sequencing of multiple Arabidopsis thaliana populations. Nat. Genet. 43, 956-963. doi: 10.1038/ng.911

Chassot, C., Nawrath, C., and Métraux, J. P. (2007). Cuticular defects lead to full immunity to a major plant pathogen. Plant J. 49, 972-980. doi: 10.1111/j.1365313X.2006.03017.x

Choquer, M., Fournier, E., Kunz, C., Levis, C., Pradier, J. M., Simon, A., et al. (2007). Botrytis cinerea virulence factors: new insights into a necrotrophic and polyphageous pathogen. FEMS Microbiol. Lett. 277, 1-10. doi: 10.1111/j.15746968.2007.00930.x

Collado, I., and Viaud, M. (2016). "Secondary metabolism in Botrytis cinerea: combining genomic and metabolomic approaches," in Botrytis - The Fungus, The Pathogen and Its Management in Agricultural Systems, eds S. Fillinger and Y. Elad (Cham: Springer International Publishing), 291-313.

De Miccolis Angelini, R. M., Rotolo, C., Masiello, M., Gerin, D., Pollastro, S., and Faretra, F. (2014). Occurrence of fungicide resistance in populations of Botryotinia fuckeliana (Botrytis cinerea) on table grape and strawberry in southern Italy. Pest Manag. Sci. 70, 1785-1796. doi: 10.1002/ps.3711

Dean, R., van Kan, J. A., Pretorius, Z. A., Hammond-Kosack, K. E., Di Pietro, A., Spanu, P. D., et al. (2012). The Top 10 fungal pathogens in molecular plant pathology. Mol. Plant Pathol. 13, 414-430. doi: 10.1111/j.13643703.2011.00783.x

Elad, Y., and Evensen, K. (1995). Physiological aspects of resistance to Botrytis cinerea. Phytopathology 85, 637-643.

Elad, Y., Pertot, I., Cotes Prado, A. M., and Stewart, A. (2015). "Plant hosts of Botrytis spp," in Botrytis - The Fungus, The Pathogen and Its Management in Agricultural Systems, eds S. Fillinger and Y. Elad (Cham: Springer International Publishing), 413-486.

Fakruddin, M., and Chowdhury, A. (2012). Pyrosequencing-an alternative to traditional Sanger sequencing. Am. J. Biochem. Biotechnol. 8, 14-20. doi: 10.3844/ajbbsp.2012.14.20

Fernández-Acero, F. J., Carbú, M., El-Akhal, M. R., Garrido, C., GonzálezRodríguez, V. E., and Cantoral, J. M. (2011). Development of proteomics-based fungicides: new strategies for environmentally friendly control of fungal plant diseases. Int. J. Mol. Sci. 12, 795-816. doi: 10.3390/ijms12010795

Fernández-Acero, F. J., Jorge, I., Calvo, E., Vallejo, I., Carbú, M., Camafeita, E., et al. (2007). Proteomicanalysis of phytopathogenic fungus Botrytis cinerea as a potential tool for identifying pathogenicity factors, the rapeutic targets and for basic research. Arch. Microbiol. 187, 207-215. doi: 10.1007/s00203-006-0188-3 
Ferrari, S., Plotnikova, J. M., De Lorenzo, G., and Ausubel, F. M. (2003). Arabidopsis local resistance to Botrytis cinerea involves salicylic acid and camalexin and requires EDS4 and PAD2, but not SID2, EDS5 or PAD4. Plant J. 35, 193-205. doi: 10.1046/j.1365-313X.2003.01794.x

Gallagher, S. R. (2006). One-dimensional SDS gel electrophoresis of proteins. Curr. Protoc. Mol. Biol. Chap. 10:Unit10.2A.

Gathungu, R. M., Bird, S. S., Sheldon, D. P., Kautz, R., Vouros, P., Matson, W. R., et al. (2014). Identification of metabolites from LC-EC profiling: GC-MS and refractionation provide essential information orthogonal to LCMS/microNMR. Anal. Biochem. 454, 23-32. doi: 10.1016/j.ab.2014.01.020

Hahn, M., Viaud, M., and van Kan, J. (2014). "The genome of Botrytis cinerea, a ubiquitous broad host range necrotroph," in Genomics of Plant-Associated Fungi and Oomycetes: Dicot Pathogens, Chap. 2, eds R. A. Dean, A. Lichens-Park, and C. Kole (Berlin: Springer-Verlag), 19-44.

Haider, S., and Pal, R. (2013). Integrated analysis of transcriptomic and proteomic data. Curr. Genomics 14, 91-110. doi: 10.2174/1389202911314 020003

Hasanuzzaman, M., Nahar, K., Alam, M. M., Roychowdhury, R., and Fujita, M. (2013). Physiological, biochemical, and molecular mechanisms of heat stress tolerance in plants. Int. J. Mol. Sci. 14, 9643-9684. doi: 10.3390/ijms14059643

Heather, J. M., and Chain, B. (2016). The sequence of sequencers: the history of sequencing DNA. Genomics 107, 1-8. doi: 10.1016/j.ygeno.2015. 11.003

Hong, J., Yang, L., Zhang, D., and Shi, J. (2016). Plant metabolomics: an indispensable system biology tool for plant science. Int. J. Mol. Sci. 17:E767. doi: 10.3390/ijms17060767

Hong, Y. S., Martinez, A., Liger-Belair, G., Jeandet, P., Nuzillard, J. M., and Cilindre, C. (2012). Metabolomics reveals simultaneous influences of plant defence system and fungal growth in Botrytis cinerea-infected Vitis vinifera cv. Chardonnay berries. J. Exp. Bot. 63, 5773-5785. doi: 10.1093/jxb/ers228

Jaillon, O., Aury, J.-M., Noel, B., Policriti, A., Clepet, C., and Casagrande, A. (2007). The grapevine genome sequence suggests ancestral hexaploidization in major angiosperm phyla. Nature 449, 463-467. doi: 10.1038/nature 06148

Jain, M., Misra, G., Patel, R. K., Priya, P., Jhanwar, S., Khan, A. W., et al. (2013). A draft genome sequence of the pulse crop chickpea (Cicer arietinum L.). Plant J. 74, 715-729. doi: 10.1111/tpj.12173

Jiang, Z., Dong, X., and Zhang, Z. (2016). Network-based comparative analysis of Arabidopsis immune responses to Golovinomyces orontii and Botrytis cinerea infections. Sci. Rep. 6:19149. doi: 10.1038/srep19149

Lai, A., Schluttenhofer, C. M., Bhide, K., Shreve, J., Thimmapuram, J., Lee, S. Y., et al. (2014). MED18 interaction with distinct transcription factors regulates multiple plant functions. Nat. Commun. 5:3064. doi: 10.1038/ncomms4064

Laluk, K., AbuQamar, S., and Mengiste, T. (2011). The Arabidopsis mitochondrial localized pentatricopeptide repeat protein PGN functions in defense against necrotrophic fungi and abiotic stress tolerance. Plant Physiol. 156, 2053-2068. doi: 10.1104/pp.111.177501

Li, B. Q., Wang, W. H., Zong, Y. Y., Qin, G., and Tian, S. (2012). Exploring pathogenic mechanisms of Botrytis cinerea secretome under different ambient $\mathrm{pH}$ based on comparative proteomic analysis. J. Proteome Res. 11, 4249-4260. doi: $10.1021 / \mathrm{pr} 300365 \mathrm{f}$

Lin, T., Zhu, G., Zhang, J., Xu, X., Yu, Q., Zheng, Z., et al. (2014). Genomic analyses provide insights into the history of tomato breeding. Nat. Genet. 46, 1220-1226. doi: $10.1038 / \mathrm{ng} .3117$

Liu, S., Kracher, B., Ziegler, J., Birkenbihl, R. P., and Somssich, I. E. (2015). Negative regulation of ABA signaling by WRKY33 is critical for Arabidopsis immunity towards Botrytis cinerea 2100. Elife 4:e07295. doi: 10.7554/eLife.07295

Magyar, I. (2011). "Botrytized wines," in Advances in Food and Nutrition Research, Vol. 63, ed. Ronald SJ (San Diego, CA: Academic Press), 147-206.

Maruyama, Y., Yamoto, N., Suzuki, Y., Chiba, Y., Yamazaki, K., Sato, T., et al. (2013). The Arabidopsis transcriptional repressor ERF9 participates in resistance against necrotrophic fungi. Plant Sci. 213, 79-87. doi: 10.1016/j.plantsci.2013.08.008

Mengiste, T., Laluk, K., and AbuQamar, S. (2010). "Mechanisms of induced resistance against B. cinerea," in Post-Harvest Pathology, Plant Pathology in the 21st century, Vol. 2, Chap. 2, eds D. Prusky and M. L. Gullino (Dordrecht: Springer Science + Business Media B.V), 13-30.
Moura, J. C., Bonine, C. A., Viana, J., Dornelas, M. C., and Mazzafera, P. (2010). Abiotic and biotic stresses and changes in the lignin content and composition in plants. J. Integr. Plant Biol. 52, 360-376. doi: 10.1111/j.1744-7909.2010.00892.x

Pareek, C. S., Smoczynski, R., and Tretyn, A. (2011). Sequencing technologies and genome sequencing. J. Appl. Genet. 52, 413-435. doi: 10.1007/s13353-0110057-x

Parween, S., Nawaz, K., Roy, R., Pole, A. K., Venkata Suresh, B., Misra, G., et al. (2015). An advanced draft genome assembly of a desi type chickpea (Cicer arietinum L.). Sci. Rep. 5:12806. doi: 10.1038/srep12806

Popescu, S. C., Snyder, M., and Dinesh-Kumar, S. (2007). Arabidopsis protein microarrays for the high-throughput identification of protein-protein interactions. Plant Signal. Behav. 2, 416-420. doi: 10.4161/psb.2.5.4416

Rabilloud, T., and Lelong, C. (2011). Two-dimensional gel electrophoresis in proteomics: a tutorial. J. Proteomics 74, 1829-1841. doi: 10.1016/j.jprot. 2011.05.040

Ramírez, V., García-Andrade, J., and Vera, P. (2011). Enhanced disease resistance to Botrytis cinerea in myb46 Arabidopsis plants is associated to an early downregulation of CesA genes. Plant Signal. Behav. 6, 911-913.

Shah, P., Gutierrez-Sanchez, G., Orlando, R., and Bergmann, C. A. (2009). A proteomic study of pectin-degrading enzymes secreted by Botrytis cinerea grown in liquid culture. Proteomics 9, 3126-3135. doi: 10.1002/pmic. 200800933

Shah, P., Powell, A. L., Orlando, R., Bergmann, C., and Gutierrez-Sanchez, G. (2012). Proteomic analysis of ripening tomato fruit infected by Botrytis cinerea. J. Proteome Res. 11, 2178-2192. doi: 10.1021/pr200965c

Sham, A., Al-Azzawi, A., Al-Ameri, S., Al-Mahmoud, B., Awwad, F., AlRawashdeh, A., et al. (2014). Transcriptome analysis reveals genes commonly induced by Botrytis cinerea infection, cold, drought and oxidative stresses in Arabidopsis. PLoS ONE 9:e113718. doi: 10.1371/journal.pone.0113718

Sham, A., Moustafa, K., Al-Ameri, S., Al-Azzawi, A., Iratni, R., and AbuQamar, S. (2015). Identification of candidate genes in Arabidopsis in response to biotic and abiotic stresses using comparative microarrays. PLoS ONE 10:e125666. doi: 10.1371/journal.pone.0125666

Shiratake, K., and Suzuki, M. (2016). Omics studies of citrus, grape and rosaceae fruit trees. Breed. Sci. 66, 122-138. doi: 10.1270/jsbbs.66.122

Shulaev, V., Sargent, D. J., Crowhurst, R. N., Mockler, T. C., Folkerts, O., Delcher, A. L., et al. (2011). The genome of woodland strawberry (Fragaria vesca). Nat. Genet. 43, 109-116. doi: 10.1038/ng.740

Smith, J. E., Mengesha, B., Tang, H., Mengiste, T., and Bluhm, B. H. (2014). Resistance to Botrytis cinerea in Solanum lycopersicoides involves widespread transcriptional reprograming. BMC Genomics 15:334. doi: 10.1186/1471-216415-334

Son, G. H., Wan, J., Kim, H. J., Nguyen, X. C., Chung, W. S., Hong, J. C., et al. (2012). Ethylene-responsive element-binding factor 5, ERF5, is involved in chitin-induced innate immunity response. Mol. Plant Microbe Interact. 25, 48-60. doi: 10.1094/MPMI-06-11-0165

Spraggins, J. M., Rizzo, D. G., Moore, J. L., Noto, M. J., Skaar, E. P., and Caprioli, R. M. (2016). Next-generation technologies for spatial proteomics: integrating ultra-high speed MALDI-TOF and high mass resolution MALDI FTICR imaging mass spectrometry for protein analysis. Proteomics 16, 1678-1689. doi: 10.1002/pmic.201600003

Staats, M., and van Kan, J. A. (2012). Genome update of Botrytis cinerea strains B05.10 and T4. Eukaryot. Cell 11, 1413-1414. doi: 10.1128/EC.00164-12

Thomma, B. P., Eggermont, K., Penninckx, I. A., Mauch-Mani, B., Vogelsang, R., Cammue, B. P., et al. (1998). Separate jasmonate-dependent and salicylatedependent defense-response pathways in Arabidopsis are essential for resistance to distinct microbial pathogens. Proc. Natl. Acad. Sci. U.S.A. 95, 15107-15111. doi: $10.1073 /$ pnas.95.25.15107

Thudi, M., Khan, A. W., Kumar, V., Gaur, P. M., Katta, K., Garg, V., et al. (2016). Whole genome re-sequencing reveals genome-wide variations among parental lines of 16 mapping populations in chickpea (Cicer arietinum L.). BMC Plant Biol. 16:10. doi: 10.1186/s12870-015-0690-3

Tomato Genome Consortium (2012). The tomato genome sequence provides insights into fleshy fruit evolution. Nature 485, 635-641. doi: 10.1038 /nature11119

Torres-Vera, R., García, J. M., Pozo, M. J., and López-Ráez, J. A. (2014). Do strigolactones contribute to plant defence? Mol. Plant Pathol. 15, 211-216. doi: 10.1111/mpp. 12074 
Tuteja, N., Gill, S. S., and Tuteja, R. (2011). "Plant responses to abiotic stresses: shedding light on salt, drought, cold and heavy metal stress," in Omics and Plant Abiotic Stress Tolerance, Chap. 3, eds N. Tuteja, S. S. Gill, and R. Tuteja (Sharjah: Bentham Science Publisher Ltd), 39-64.

van Kan, J. A. (2006). Licensed to kill: the lifestyle of a necrotrophic plant pathogen. Trends Plant Sci. 11, 247-253. doi: 10.1016/j.tplants.2006.03.005

van Kan, J. A., Stassen, J. H., Mosbach, A., van der Lee, T. A., Faino, L., Farmer, A. D., et al. (2016). A gapless genome sequence of the fungus Botrytis cinerea. Mol. Plant Pathol doi: 10.1111/mpp.12384 [Epub ahead of print].

van Loon, L. C., Rep, M., and Pieterse, C. M. J. (2006). Significance of inducible defense-related proteins in infected plants. Annu. Rev. Phytopathol. 44, 135-162. doi: 10.1146/annurev.phyto.44.070505.143425

van Loon, L. C., and Van Strien, E. A. (1999). The families of pathogenesisrelated proteins, their activities, and comparative analysis of PR-1 type proteins. Physiol. Mol. Plant Pathol. 55, 85-97. doi: 10.1006/pmpp.1999.0213

VanEtten, H. D., Mansfield, J. W., Bailey, J. A., and Farmer, E. E. (1994). Two classes of plant antibiotics: phytoalexins versus "phytoanticipins". Plant Cell 6, 1191-1192. doi: 10.1105/tpc.6.9.1191

Varshney, R. K., Song, C., Saxena, R. K., Azam, S., Yu, S., Sharpe, A. G., et al. (2013). Draft genome sequence of chickpea (Cicer arietinum) provides a resource for trait improvement. Nat. Biotechnol. 31, 240-246. doi: 10.1038/nbt.2491

Veronese, P., Nakagami, H., Bluhm, B., AbuQamar, S., Chen, X., Salmeron, J., et al. (2006). The membrane-anchored BOTRYTIS INDUCED KINASE1 has distinct roles in Arabidopsis resistance to necrotrophic and biotrophic pathogens. Plant Cell 18, 257-273. doi: 10.1105/tpc.105.035576

Wang, X., Basnayake, B. M. V. S., Zhang, H., Li, G., Li, W., Virk, N., et al. (2009). The Arabidopsis ATAF1, a NAC transcription factor, is a negative regulator of defense responses against necrotrophic fungal and bacterial pathogens. Mol. Plant Microbe Interact. 22, 1227-1238. doi: 10.1094/MPMI-22-10-1227

Warren, R. L., Sutton, G. G., Jones, S. J. M., and Robert, R. A. (2007). Assembling millions of short DNA sequences using SSAKE. Bioinformatics 23, 500-501. doi: 10.1093/bioinformatics/btl629

Windram, O., Madhou, P., McHattie, S., Hill, C., Hickman, R., Cooke, E., et al. (2012). Arabidopsis defense against Botrytis cinerea: chronology and regulation deciphered by high-resolution temporal transcriptomic analysis. Plant Cell 24, 3530-3557. doi: 10.1105/tpc.112.102046

Yadav, S., Yadav, D. K., Yadav, N., and Khurana, S. M. P. (2015). "Plant glycomics: advances and applications," in PlantOmics: The Omics of Plant Science eds D. Barh, M.S. Khan, and E. Davies (New Delhi: Springer Publisher), 299-329.

Zhao, L., Huang, Y., Hu, J., Zhou, H., Adeleye, A. S., and Keller, A. A. (2016). $1 \mathrm{H}$ NMR and GC-MS based metabolomics reveal defense and detoxification mechanism of cucumber plant under nano-Cu stress. Environ. Sci. Technol. 50, 2000-2010. doi: 10.1021/acs.est.5b05011

Conflict of Interest Statement: The authors declare that the research was conducted in the absence of any commercial or financial relationships that could be construed as a potential conflict of interest.

Copyright (C) 2016 AbuQamar, Moustafa and Tran. This is an open-access article distributed under the terms of the Creative Commons Attribution License (CC BY). The use, distribution or reproduction in other forums is permitted, provided the original author(s) or licensor are credited and that the original publication in this journal is cited, in accordance with accepted academic practice. No use, distribution or reproduction is permitted which does not comply with these terms. 